"This is an Accepted Manuscript of an article published by Taylor \& Francis in Social and Cultural Geography online 9 May 2016, available online: http://www.tandfonline.com/doi/full/10.1080/14649365.2016.1180 $\underline{424}$

\title{
Therapeutic landscapes and non-human animals: the roles and contested positions of animals within care farming assemblages
}

\author{
Richard Gorman ${ }^{*}$ \\ aSchool of Geography and Planning, Cardiff University, Glamorgan Building, King Edward VII \\ Avenue, Cardiff, CF10 3WT
}

(Received 10 November 2015; accepted 29 February 2016)

\begin{abstract}
The concept of therapeutic landscapes has been used as a way to critically understand how health and wellbeing are related to place. However, traditional discourses on therapeutic landscapes have been constructed from an anthropocentric perspective, completely ignoring and silencing the agency and experiences of non-humans. Building on the idea of therapeutic spaces as assemblages, I highlight the heterogeneity of elements that come together to produce therapeutic space. Mobilising empirical research undertaken in spaces involved in the practice of 'care farming', I demonstrate how non-human presence actively creates and facilitates a therapeutic engagement with place. However, with this recognition of the non-human in therapeutic spaces, there is a need to discuss animals' contested positions, and question the ways in which being part of these assemblages impacts animals; for whom are these landscapes therapeutic? Thus, this article advocates a critical understanding of the role of non-human animals as both co-constituents and co-participants of therapeutic spaces, moving from framing therapeutic spaces - and the animals within them - purely in relation to human needs and desires.
\end{abstract}

Keywords: therapeutic landscapes; care farming; human-animal relations; more-than-human; animal geography; post-humanism

\section{Introduction}

'Some people talk to animals. Not many listen though. That's the problem' - Milne 


\section{R. Gorman}

Since Gesler first wrote about the concept of 'therapeutic landscapes' in 1992, geographers have actively and critically engaged with the concept as a way of understanding how perceptions, reputations and experiences of health come to be associated with spatial areas (DeVerteuil et al. 2007). The phrase has been used extensively as 'a conceptual framework to organise ideas about how people experience landscape in ways that are important to their health' (Curtis 2012, p.7). However, as this paper will highlight, much of the research on therapeutic landscapes has been anthropocentric, ignoring and silencing the agency and experiences of non-humans, something which this article aims to challenge and deconstruct.

I begin by briefly reviewing the therapeutic landscape literature and some of the criticisms which have been levelled at the concept, exploring how geography's growing interest in assemblage theory (Anderson and McFarlane 2011) helps to move beyond static, universal, and absolute conceptualisations of homogenous therapeutic spaces. Taking this theoretical approach results in a need to more critically unpack the heterogeneity of therapeutic spaces, I thus move to focus on the role (or more specifically, the problematic lack of role) given to nonhumans, animals specifically, within existing research. In order to address this, I bring the literature on therapeutic spaces into conversation with recent arguments made within animal geographies and wider post-human discourse, mobilising ideas and arguments that there is a need to allow a sense of animals as animals, rather than as surfaces onto which humans project their needs and desires (Philo and Wilbert 2000). By opening a dialogue between these two literatures, it becomes clear that there is a need to decentre humans in 
discussions of therapeutic spaces and instead begin to consider a post-human and multispecies approach that rejects the prioritization of human-centric norms, assumptions, behaviours, and practices (Wilkie 2013).

Based on data collected during an empirical study of care farms in England and Wales, I will discuss and apply these ideas and talk about how nonhuman agency can create and facilitate a therapeutic engagement with place, whilst simultaneously intruding and disrupting therapeutic processes highlighting the somewhat ambiguous and unstable role of non-human animals within therapeutic spaces. I will also touch on how non-human animals coconstitute therapeutic space, and how thinking of these spaces as multispecies begins to disrupt some of the established notions of the therapeutic landscape concept, before positing ideas for a more biosocial framing of therapeutic affect that I suggest provides a more post-human way to explore and critically understand human-animal relations in a wide variety of therapeutic spaces.

\section{Therapeutic spaces}

A variety of conceptualisations of therapeutic landscapes has emerged since Gesler's (1992) first discussion of the phrase. Therapeutic landscapes have been described in physiological terms, generating relief from physical symptoms and assisting in reducing stress (Marcus and Barnes 1999). Other utilisations of the term highlight how space can improve and support a person's emotional and social wellbeing (Tyson 1998) - indeed, therapeutic landscapes are often described as being as much about social opportunities as they are medicinal 


\section{$4 \quad$ R. Gorman}

(Foley et al. 2011). Later uses of the concept have demonstrated how rather than explicitly providing a curative factor, therapeutic landscapes are often framed as supporting a maintenance of health and wellbeing, or even providing opportunities for an individual's capacity building (Ingen 2004; Leach et al. 2008).

More recently, there has been a move within literature to refer simply to 'therapeutic spaces,' dropping the 'landscape' aspect of the concept, as a means of beginning to recognise the more-than-terrestrial spaces which can impact on health and wellbeing (Foley and Kistemann 2015) and broaden the ways in which geographers engage with ideas of health and place. Indeed, the wording of 'landscape' in the titling of the concept is perhaps something of a misnomer, often leading to an over-focusing on the physical environment, indeed Gesler (1992) lamented that 'the first reaction one encounters when mentioning therapeutic landscapes is that what is meant is bucolic locales, health spas, and the like' (p.743). Instead, the concept's application of landscape draws on a more cultural approach, recognising landscape as a dynamic and evolving process, molded by the meshing and imbrication between physical, individual, and social factors (Gesler 1992).

Given this, it is perhaps then appropriate that increasingly deployments of the therapeutic landscapes concept have moved to viewing space as relational (Conradson 2005), recognising that there are no essential qualities to any given space (Murdoch 2006). Instead, the physical space of a therapeutic landscape becomes important only in its relation to the meaning that is prescribed 
(Williams 1999). In this way, the 'therapeutic' nature of the space is emergent from relational configurations assembled and co-produced through a series of heterogeneous actants, events, practices and processes which gather, disperse and entangle multiple timespaces, rather than inherent in the space itself.

As a result, no singular space emerges to provide a positive health experience for everyone; what constitutes therapeutic for one (human or nonhuman) may not for another, even potentially causing harm rather than health (Williams 2007). Conradson (2005) draws on the idea of the 'relational self' to highlight this fluidity, noting that a therapeutic landscape experience will be influenced by reconfigurations of the relational self as individuals move through space, becoming imbricated with different sets of relations. Ambiguities exist then amongst the relations that can affect a space 'becoming therapeutic'. Therapeutic spaces are neither constant nor stable, impacted by a variety of factors and relations: wider social, economic and political factors (Gesler 1998), a person's mood (Laws 2009), media attitudes towards specific place types and sensationalist news stories (Milligan 2007), even changing seasonally and diurnally (Collins and Kearns 2007). However, one set of relations yet to be discussed within the context of therapeutic landscapes is the non-human element of these spaces, despite the growing popularity of multispecies scholarship (Wilkie and McKinnon 2013).

Indeed, applications of the therapeutic landscape concept have often failed to discuss the heterogeneity of elements that come together to produce therapeutic space, viewing the spaces they discuss as static and delineated. More 


\section{R. Gorman}

recent work by Wood et al. (2015) has noted that many people situated within therapeutic landscapes come to view the spaces as 'dynamic, changing environments' (p.87), often leading to disputed spaces and tensions within the concepts deployment. There is a need to move from such rigid conceptualisations to an understanding that recognises the fluidity, multiplicity, contingency and indeterminacy of therapeutic landscapes. On this basis, Foley (2014) suggests applying post-structuralist theory to the therapeutic landscape concept, and moving towards understanding these spaces as 'therapeutic assemblages'.

Assemblage is a term increasingly being used in geographical scholarship as a way to describe a substantive range of phenomena; a way to remove bordered thinking, an ethos of engagement attuned to possibilities, and an ontology orientated to the possibility of the uncertain (Anderson and McFarlane 2011). At its simplest, assemblage is about emergence, multiplicity, and indeterminacy, and proves a useful way to understand how the on-going gathering, coherence, and dispersion of things and relations, through processes of change and disruption, lead to the formation of specific therapeutic geographies and the opening up and closing down of therapeutic possibilities.

Foley (2014) suggests that applying assemblage thinking to therapeutic spaces would enable scholars to think through the different relationships at play within spaces of health, paying attention to the subjects and objects that are components of the assemblage, creating a more 'inhabited' understanding. This perhaps creates a way of manoeuvring around Andrews' (2004) critique that a 
lot of therapeutic landscape research simply applies a 'bumper sticker' to phenomena, creating a dichotomy of viewing space as either therapeutic or not therapeutic (Wilton and DeVerteuil 2006). This idea of a more inhabited approach also draws attention to the fact that therapeutic assemblages are not simply inhabited by purely human actants, being comprised of non-human elements that additionally shape the spaces. It is the matter of animals that I now turn to in order to build on the idea of therapeutic assemblages, by focussing deeply on the heterogeneous and non-human nature of the elements that can come together to produce therapeutic spaces.

\section{Where are the animals?}

Wolch and Emel's (1995) call for 'bringing the animals back in' does not appear to have permeated into discussions of therapeutic spaces - to date there has been little research exploring the role of non-humans in therapeutic landscapes; animals have instead been subsumed into the broader concept of 'nature' within discourses surrounding therapeutic landscapes. Often discussed is how 'wild' landscapes can evoke therapeutic experiences (Palka 1999), yet there is a need for a more in-depth discussion of what constitutes this 'wild'. Forests are another recurrent theme within the existing therapeutic landscape literature (Milligan and Bingley 2007; Morita et al. 2007; Thurber and Malinowski 1999), yet again 'forest' is more often than not used as a homogenous descriptor, with the diversity of heterogeneous actants which comprise therapeutic forest spaces left unmentioned. 
Despite a lack of acknowledgement of animals in studies of therapeutic spaces, there is a wide body of literature (much of it admittedly outside of geographical scholarship) which has catalogued the health benefits which nonhumans can effect for humans, leading Beck and Katcher (2003) to summarise that 'There is solid evidence that animal contact has significant health benefits and that it positively influences transient physiological states, morale, and feelings of self-worth' (p.87).

Animals can facilitate human social contact, self-efficacy and self-esteem, as well as acting as a form of social support, particularly through serving as attachment figures and offering an emotional bond, secure base and a representation model (Berget and Braastad 2008). Human-animal interaction has been shown to have a range of positive influences on varying groups of humans: reduced autistic symptoms, improved self-esteem, reduced loneliness and increased interaction in social situations to more physiological changes such as improved motor skills, reduced anxiety and reduced blood pressure (Odendaal 2000; Urbanik 2012). Animals can provide a diversion and distraction from everyday stresses and pains, and caring for animals can create a purposeful routine (Barba 1995). Emotional bonding with other species can help to satisfy human emotional needs and enhance emotional capacity (Kellert 1996). For some people, simply observing animals can be therapeutic (Zeisel and Tyson 1999). Animals as well can function as a powerful semiotic force, contributing to the formation of positive health perceptions and experiences (Mallon 1994). Hodgson and Darling (2011) coined the term 'zooeyia' to refer to the positive benefits to human health from interacting with animals - though their specific 
focussing on a more traditional definition of 'companion animals' (dogs, cats, etc.), somewhat limits its utility for these discussions; there exists a much wider variety of species which may become companionable (Haraway 2008) within therapeutic spaces.

At the same time as recognising these potential benefits from interspecies encounters, we must recognise that the subjective and shifting relations which compose therapeutic landscapes also affects human-animal interaction relationships and encounters between people and animals are multi-determinate (Berget and Braastad 2008). Not all interaction with animals will be inherently positive; there is the possibility for bites, anaphylaxis, parasites and poorlytempered animals (Barba 1995). Phobias and negative past experiences with animals may also result in different experiences (Milligan and Bingley 2007; Odendaal 2000), ultimately creating spaces which are therapeutic to certain individuals and social groups, but not others. Animals then, as with the wider concept of therapeutic spaces, are not guaranteed to create relations that can create a therapeutic experience for all.

Animals' roles in therapeutic landscapes are far from stable, their acceptance into these spaces of health, ambiguous. Exclusion has been recognised as an important factor in therapeutic landscapes (Kearns and Gesler 1998), and this is no different when discussing the exclusion of non-humans. The absence and barring of certain species can be framed as crucial to the emergence of health; intrusion by non-humans can disrupt therapeutic processes (Dunkley 2009). In more extreme cases of intrusion, animals can be the specific cause of 


\section{R. Gorman}

effecting negative health and wellbeing for humans (Jadhav and Barua 2012). In certain contexts animals can find their relationships reconfigured from effecting a therapeutic experience to becoming infectious agents or health hazards (Law and Miele 2011). Animals lack a permanency, despite often being seen as integral to landscape identities.

When thinking about 'bringing the animals back in' to discussions of therapeutic landscapes, it may seem natural to begin to bring back and think about large and encounterable charismatic species,, but we must also recognise the microbiome; microorganisms and protozoans can certainly effect health experiences - and many of these species may already be engaged in existing relations and symbioses with the more visible and apparent non-humans within therapeutic spaces. We must be careful not to side-line invisible, uncomfortable, and unloved species (Ginn 2013).

\section{More-than-human therapeutic spaces}

Different actants experience encounters and spaces differently, being active agents in co-producing place, thus, what constitutes a therapeutic space for one may not for another (Williams 2007). Numerous authors writing on therapeutic landscapes have discussed how various personal factors can alter one's experience of a therapeutic space: illness or disability (Kearns and Gesler 1998), age (Milligan et al. 2004), nationality and cultural background (Chang and Relf 2004; Marcus and Barnes 1999), socio-economic status (Kearns and Joseph 1993), gender, class, race, and sexuality (Ingen 2004), creating spaces which are 
therapeutic to certain groups, but not others. Not discussed at present is species, and how biological identity can effect these spaces' potential to become therapeutic; what a human experiences as a therapeutic space may be untherapeutic for an animal. Although importantly, in the same way that not all humans experience space in the same way, nor do all animals, nor even all members of a species. There is a need for a conceptual framework to allow these questions to be explored empirically; I wish to begin to propose ways of thinking that will allow research to attend to the more-than-human nature of therapeutic spaces.

The animal turn has led to a recognition of animals as subjects, individual experiential beings with their own lives, social actants participating in agential relationships; therefore we should ask, for whom are these landscapes therapeutic, all beings, or simply (some) humans? What do animals get out of being enrolled in therapeutic practices and spaces? The life-practices of nonhuman actants are potentially in conflict with human conceptions of therapeutic spaces (or at least, certain human social groups); animals are attempting to live their own lives, their desires and intentions do not necessarily coincide with human wills or understandings of therapeutic space.

At first, it may seem as though the very idea of attempting to conceptualise a space as a 'therapeutic landscape' is a purely human process, however, animals too are actively involved in processes of place making (Lorimer 2006). There is a need to extend the notion of care to non-human relationships whilst also initiating a more thorough exploration of modalities of 


\section{R. Gorman}

sharing therapeutic spaces with non-human others, de-centring humans and beginning to consider a multispecies approach to therapeutic landscapes (Doughty 2013; Milligan and Wiles 2010).

Discussions of therapeutic encounters with animals mainly focus on the human experience of the interaction, the framing of therapy is purely in relation to human needs and desires, often resulting in a somewhat imperialist attitude of health being just another resource to be harvested from non-humans (Malamud 2013). There is some recognition that human participants may provoke or injure animals through aggressive behaviour, and that some animals may be unable to cope with excessive noise or activity (Barba 1995; Mallon 1994). It is worth remembering that within these therapeutic spaces, it is specific and individual non-humans which are enrolled, each with their own life histories and experiences, which will change the way they respond and engage (Bear and Eden 2011).

There is a very real need to recognise and understand the presence of animals in therapeutic spaces; Hassink (2002) warns that a focus on optimising the welfare of human participants on a farm may result in a converse reduction on animal welfare - indeed, Mallon (1994) suggests that it is 'mastering' and dominating an animal which results in therapeutic benefits for humans; how does this human-centrism and dominance impact on animals' experiences within therapeutic spaces? Scholl and Demattio (2007) discuss how animals used on care farms should be socialised and trained. Does this result in a denial of agency and the exclusion and ejection of animals who do not behave to appropriate 
human standards? They go on to describe how the Austrian Council for Agricultural Engineering and Rural Development planned to introduce an examination system to assess individual animals before allowing their involvement on care farms - yet humans do not have to be assessed before their involvement - suggesting these care farm spaces are being constructed and performed to evoke health experiences for a solely human audience, with the non-human relegated to a state of utility rather than as co-beneficiaries of the positive effects.

Returning briefly to the concept of zooeyia (the idea of positive health benefits from animals), we find that introducing a more-than-human focus becomes problematic, with zooeyia specifically focussed on 'the human health benefits from animals...the positive impact on human health' (Hodgson and Darling 2011, p.189, emphasis added), the animal experience and any crossspecies mutualism of these exchanges is silenced, with non-humans being 'jettisoned as subjects of health in their own right, being reaffirmed as utilitarian handmaidens' (Hanrahan 2014, p.38). We need concepts for recognising multispecies spaces of health which move beyond the anthropocentric duality of animals as either risks or benefits (Hanrahan 2014), but affirms animals as individual social actants with their own lived experiences of healthcare spaces and practices.

Recent work by Leck et al. (2014) investigating care farms as therapeutic spaces, found interviewees explicitly recognised the role animals play in human wellbeing: '[livestock] are crucial to the process of achieving personal and 


\section{R. Gorman}

collective well-being' (p.320). The authors use this to suggest that experiences of care can be reciprocal between human and non-human: therapeutic landscapes and meetings between species do not have to be limited to humanistic and utilitarian codings.

Through recent reconceptualizations of 'the social' as being constituted not solely by human actants (Haraway 2008), it might be suggested that we need to become sensitive to a range of different species' embodied experiences of therapeutic spaces and encounters, and account for animal presence and agency in a way that illuminates other ways of being in the world; clarifying interspecies social connectedness, in a 'social' that is not purely constituted by human actants (Kirksey and Helmreich 2010). Therapeutic spaces are complex, multispecies spaces, containing messy and multiple entanglements of all sorts of different organisms, all with a diversity of different ways of living and being; we live a multispecies life whether we like or know it (Cudworth 2011). We cannot simply forget, or refuse to acknowledge the non-human actants that are present, within, and sharing therapeutic spaces. I suggest there is a need for studies of therapeutic spaces that explore how non-human presence and agency influences the (un)therapeutic nature of space, but also, going one step further, and beginning to think about the non-human experience of these therapeutic spaces.

\section{Methodologies for exploring everyday agricultural therapeutic spaces}

My empirical research takes the form of exploring Community Supported Agriculture (CSA) projects, a system of food production and distribution aiming 
to involve local communities in the growing and rearing of their food. CSA itself covers a wide range of different partnerships between consumers and producers; there is a broad array of different models of CSA and stakeholders involve themselves for a wide range of reasons.

Although they are not specifically designated as places of health, CSA farms are often connected with producing health benefits; many claim to offer improved health from eating the local (and often organic) produce grown, taking part in physical activity and volunteering on the farm, or simply being outdoors with nature (Cooley 1996; Stagl 2002). Health thus emerges as an affect produced through the diverse relations and elements gathered together to form community supported agriculture assemblages, and provides an interesting interrogative frame through which to critically explore how more everyday spaces can become therapeutic landscapes.

An everyday approach has generally been neglected in this way within studies of therapeutic landscapes, instead focussing on extraordinary and unique places (for example, Gesler's (1996) study of pilgrimages at Lourdes, or Williams' (2010) study of the Basilica of Sainte-Anne-de-Beaupré), places specifically designated as spaces of health, instead of recognising that therapeutic experiences can emerge from everyday landscapes (Wilson 2003). Further, therapeutic landscape research has often been overly focused on the interactions of visitors or patients with therapeutic landscapes, rather than residents living in such areas (Dobbs 1997), despite Gesler (1992) stressing the potential of 


\section{R. Gorman}

'rootedness' as being a beneficial relation, assisting in enabling a therapeutic experience by creating identities, security, and belonging (Gesler 2003).

CSA offers an interesting research angle in this regard, containing farmers who live permanently on site, for whom the landscape is very much everyday, and subscribers and volunteers, who visit the farm for shorter periods of time. Although, there is a need to recognise that for many visitors, it is at first, the extraordinary nature and difference of the farm environment which leads to their visitation and subsequent experience of the landscape as therapeutic; the very fact that the farm is far from what they might experience on an everyday basis. However, as they become more regular visitants to the farm, this becomes blurred, as people become more and more embedded, the place becoming more everyday:

'There is a constant backdrop of birdsong - though people don't notice it after becoming regulars at the farm. I remember on my previous visits, people used to remark on the birdsong, yet now, it has simply become a placebased feature, which people expect \& understand as just a part of what the farm is.' [Fieldnotes, 6 August 2015].

27 semi-structured interviews were conducted between December 2014 and August 2015 in England and Wales, with farmers and managers of food producing CSA farms with animals. These interviews were fully transcribed and coded using NVIVO to identify themes and patterns. A farm in West Wales was then selected (utilising the case selection criteria developed by Curtis et al. 
(2000) for qualitative research in health geographies) for further ethnographic research (between March 2015 and September 2015) to generate richer and deeper insight into the cultures, relations, performances, technologies, and bodies gathered together within the CSA assemblage. An additional 4 interviews were conducted (simultaneously to this ethnographic work) with external organisations (a local council run scheme, a college, and a charity) involved in bringing vulnerable groups onto the farm to benefit from what they perceived to be a therapeutic space.

Whilst all of the interviewed farms kept animals (mostly livestock species given the agricultural context, but some 'pet' animals too. One interviewed farm even had reindeer!), the multiple models of CSA and diversity of subscribers meant that the animals involved were portrayed as having a multitude of different roles, existing as sources of food, producers of food, or sources of a (therapeutic) animal encounter - with their positions often fluidly shifting between these, or fulfilling multiple roles simultaneously: friend one day, food the next.

Recognising that spaces of agriculture are not always purely focussed on food production (Ilbery and Bowler 1998), some of the interviewed CSA farms actively engaged with the idea of being a therapeutic space, and attempted to create ways for the space of the farm to provide benefits to various groups, inviting people into the farm environment, and working in partnership with external organisations. To an extent the CSAs came to function informally, or at 


\section{R. Gorman}

times specifically, as care farms, a form of farming combining agricultural production with health, social, and educational services (Hassink et al. 2010).

'We have organised visits from care homes and often many of the residents once worked on farms and love to see the animals' $[\mathrm{C}$, farm manager, South West England].

There can be seen to be some interesting crossover between CSA and Care Farming as models of agriculture; both seek to reintegrate agriculture into wider society (Adam 2006; Hassink 2002) and educate participants about nature and food (Cooley and Lass 1998; Hine et al. 2008), both utilise non-labourers (clients or subscribers) as a workforce (Groh and McFadden 2000; Hassink et al. 2012) and both are rooted in the holisticism of biodynamic agriculture (Groh and McFadden 2000; Sempik 2008). Care farming can also be framed as a way to reconnect people to the land and to food systems (Hine 2007), creating parallels with the aims of many community supported agriculture farms (Groh and McFadden 2000).

However, despite these apparent links, the extent to which these places of food production existed as explicit providers of care varied. Some explicitly mobilised farming practices as a way of promoting mental and physical health, others identified and functioned more within the paradigm of more traditional agricultural production, but nonetheless, existing in an everyday space that for some individuals had the potential to become therapeutic. Some farms followed a more traditional care-farming approach, providing therapy, training, and work 
experience for people with learning disabilities and mental health issues, whilst others looked to provide opportunities for a much wider range of groups, extending from people at risk of substance abuse, people within the criminal justice system, people at risk of homelessness, and disengaged young people. This in itself provided an interesting way of exploring therapeutic spaces and highlighting that the concept is not limited strictly to purely medicinal interpretations of health and care, but also peoples' wider social wellbeing. The diversity of participants visiting the farms also highlighted the multiplicity of ways in which humans and animals engage with each other, and the therapeutic potential that animal encounters can have for a range of social groups.

Following my earlier arguments for more explicit recognition of the role of animals in therapeutic spaces, the next two sections draw on my empirical work to show how the agency of non-human social actors can affect a place's reputation as a therapeutic landscape, and to explore animals' contested positions within therapeutic spaces. Through this, I question the ways in which being part of these assemblages impacts animals; for whom are these landscapes therapeutic?

\section{Animals co-constituting therapeutic spaces}

There is no denying the presence of animals within care farms; the assemblages I was exploring were filled with a vibrancy of animal life. There were the regular assortment of domestic species found within agricultural spaces - pigs, cattle, horses - as well as more transient non-humans, such as bluebottles, buzzards, 


\section{R. Gorman}

and bees. The animals were vital parts of the farm assemblage - crucial to maintaining the everyday fabric of an understanding of 'the farm'; key coconstituents of place-making and experience-producing. Recognising animals' explicit presence in these spaces, there is a need to critically examine their roles in co-constituting a therapeutic space, and how animal encounters, and the agency of non-humans themselves can be vital in creating an association of a place being therapeutic.

'The guys quite often go over and see the sheep, and we'll walk down to see the chickens, it's of interest, it's different, it's stuff they won't see every day in their back gardens in town' [Q, outdoor activities coordinator, West Wales].

The volunteers and/or service users get involved with a range of tasks that bring them into direct material, bodily and sensorial encounters with the range of non-human life on the farms: feeding the animals, cleaning them out, moving the animals from field to field. There is a lot of tactile contact with nonhuman others - though it perhaps helps that many of the animals drawn into the farm assemblage tend to be cute, cuddly and comforting.

'When kids come along and the chickens fly up on their shoulder, they just look really happy at that point' [B, farmer, Southwest England].

Animals come to affect the emotional geographies of the space, giving participants something to nurture, something spontaneous to react to and interact with, for some people, even triggering memories and a sense of 
familiarity. This links to Rose's (2012) suggestion that individuals can encounter therapeutic landscapes as an 'empathic mirror of feeling states and affects' (p.1385), in order to realise a therapeutic benefit. Animals can act as this mirror, serving as attachment figures and representation models, providing a secure base, and offering the opportunity for emotional bonds (Berget and Braastad 2008).

'People laugh a lot, you know, when we're rounding up the sheep hopelessly, like 15 of us trying to round up a field of sheep with loads of kids' [R, farmer, West Wales].

Though as mentioned earlier, animals are not guaranteed to create relations which result in a space becoming therapeutic and instead may result in the creation of a 'landscape of fear' (Tuan 1980): 'One girl warned me before we went out, 'are there any birds there?', 'no I said, there's no birds', thinking that there's no birds. When we arrived, they had chickens, there were chickens running around, and I saw, just an absolute phobia, she said, 'I can't go anywhere near, I can't do it, I've got to get back on the bus" [J, staff member taking students with learning disabilities to animal projects, West Wales]. The individualised and personal reactions to encounters with non-humans creates interesting tensions and politics within therapeutic spaces; there is the potential for othering those who have specific and different reactions to animals (Smith and Davidson 2006). It also highlights the importance of recognising the role of the individual in interpreting and designating a place as therapeutic, what constitutes therapeutic for one person may not for another, emphasising the importance a relational 


\section{R. Gorman}

approach (such as assemblage theory) can bring in moving from static, universal, and absolute conceptualisations of therapeutic landscapes to instead recognising the fluidity, multiplicity, contingency and indeterminacy of these spaces.

As well as impacting the emotional geographies of space, the animals affect the social dynamic of the therapeutic space; their bodies and presence become key relations in creating and facilitating social contact amongst the human participants: 'That's where the animals come into it as well, that brings in their social thing ... they can sit around and ask each other about their pets, it's just those tiny little conversations that actually people wouldn't normally have, it's quite good' [A, animal coordinator of a care farm, East England]. The animals' agency creates something to engage with and respond to for the participants on these farms, often prompting social interactions that the participants may not have in a different therapeutic space, devoid of non-human life.

Further, the animals create shared relations and a commonality of knowledges and experiences between people, regardless of their background and abilities; 'The main volunteer group we have, he brings this big old brown Labrador, and the dogs, particularly his Labrador thinking about it, is a real focus of conversation, when we have a tea-break, the dog will lie in the middle of everyone and everyone will pet it, he kind of really holds things together' [R, farmer, West Wales]. 'It's like a sense of belonging ... they've got to know Mambo and the names of these dogs, and they're like 'oh Mambo', and they like to feel as if they belong' [Z, opportunities coordinator, West Wales]. 
Topographically distant animal actants too come to be mobilised in this way as a result of these initial animal encounters (again, highlighting the value of drawing on assemblage theory's flat ontology which destabilises scale and distance) (Bear 2013): 'When we're handling rabbits or grooming rabbits or something 'oh yeah, my rabbit does this' and you know, that sparks off a bit of conversation' [A, animal coordinator of a care farm, East England]. Memories and emotions associated with other animals can be stirred by contact with another member of the species, bringing in individuals' pre-existing knowledge and affinities with non-humans to play a role in the therapeutic becoming of their actual topographic location.

The animals are very much important in the way in which participants feel comfortable with the space and begin to develop a level of ownership of the environment too. As an outsider coming in to observe, the participants were very keen to share their memories and knowledge of the animals, telling individualised stories about the animals, or demonstrating their abilities to get the farm dogs to perform their full repertoire of tricks. This links to Gesler's (1992) emphasis on the therapeutic potential of prolonged experience of particular spaces, as well as the dwelt knowledge of place, suggesting themes of place attachment (Low and Altman 1992). However, here, it is particularly the prolonged experience and dwelt knowledge of the non-human lives sharing and co-habiting the space that is instrumental in assisting the place's becoming therapeutic: 'It's down to a sense of belonging and identity' [Z, opportunities coordinator, West Wales]. 


\section{R. Gorman}

However, the potential for the development of a bond in this way between a participant and an animal is obfuscated by the agricultural setting in which the care farms operate: 'The kids hadn't wanted the cockerels to be killed. $K$ thought this was because the cockerel had never intended to be killed, and thus they had all grown too attached to it, she noted that with the other animals that were for eating, they had known this from the start, allowing them to place some distance to begin with.' [Fieldnotes, 22 May 2015]. The use of livestock for therapeutic encounters then has the potential to be a double-edged sword, providing the opportunities for beneficial encounters, but with the risk of emotional stress for participants when the time for slaughter comes within the agricultural cycle.

Animals were also used to create a way of encouraging physical and healthy activity, without it being framed explicitly as exercise - whether walking a dog, or trekking across a field with a wheelbarrow full of sheep-feed. These activities were beneficial, as they were meaningful - not physical activity simply for the sake of physical activity, but purposeful tasks, with a value, and endresult attached to them. Pitt (2014) draws upon Csikszentmihalyi's (2009) concept of flow to explain how activities allow people to become absorbed, screening out negative perceptions - thus spaces with specific activities may be more likely to become therapeutic. Though we must also recognise that for some, it is the specific absence of activities that leads to a space becoming therapeutic (Conradson 2007). It is often activities which have an explicit reputation for health or wellbeing themselves (running (Ingen 2004), yoga (Hoyez 2007), hiking and walking (Doughty 2013)) that have been explored in relation to therapeutic spaces, however there is also a need to examine activities which are 
extraneous to health, the mundane and everyday tasks which can take place within spaces linked to therapeutic experiences and may, for some individuals, be crucial relations in assisting in the space becoming therapeutic.

Animals also act to reframe and reposition many of the participants on the farms; 'I think the animals add a touch of magic really, one of the big things here is for all these guys, they are cared for, and actually, when they come here, they get to care for something. It completely changes it, and gives them a sense of confidence and wellbeing, and sort of self-worth, that they kind of get a role change' [Y, manager of a care farm, East England]. Animals initiate a change from Care Recipient to Care Giver, enhancing participants' self-confidence and self-image, reframing them as capable. The non-human presence actively creates and facilitates a therapeutic engagement with place, influencing not only how people experience health and care on the farm, but also how they visualise themselves; a reconfiguring of the relational self, caused by the participants becoming imbricated with non-human actants (Conradson 2005). Similarly to Foley and Kistemann's (2015) discussions of therapeutic blue spaces, the farms have emotional and life course resonances that extend far beyond specific single encounters; an affective journey through and with the therapeutic space that creates a long-lasting therapeutic relation even once the physical site of the therapeutic landscape is left. It is an affect made possible by bringing (or simply embracing the presence of) the non-human into a therapeutic space, and deliberately creating the opportunities for inter-species encounters.

\section{Animals' contested positions within therapeutic spaces}


Whilst the above discussion may highlight how animals can aid in space becoming therapeutic for humans, there is also a need to critically think about animals' contested positions within therapeutic spaces, and question the ways in which being part of these assemblages impacts the individual animals themselves (though obviously, we cannot question the animals themselves). There is a danger of elevating the human experience of therapeutic space above that of the animals that help to co-constitute the therapeutic assemblage, relegating non-humans to a state of utility or even becoming a relationship of amensalism or parasitism. I have discussed extensively how animals act as coconstituents of therapeutic space for humans, but there is also a need to consider how humans effect therapeutic space for non-humans: 'I don't know if they'd be bothered if we weren't here or not, they'd probably be just as happy, they probably find us a bit of a hassle' [X, director of a CSA project, West Wales]. 'The volunteers are always interested in the animals, and seeking contact with them. The sheep however, are fairly aloof and generally don't let the volunteers approach them.' [Fieldnotes, 7 May 2015]. Animals are not simply the recipients of human action, devoid of agency themselves. Yet there is a danger that they do become positioned more as tools to provoke a therapeutic encounter, rather than as actants sharing the space.

There is also perhaps the irony for the animal participants that the therapeutic spaces I have been exploring are based within the sphere of agriculture. Hine et al. (2008) characterise care farms as existing on a scale ranging between a focus primarily on agricultural production, or focussing more 
on the provision and production of care. For animals on farms with a latter focus, many may be there more as pets or with the farm serving as a form of animal sanctuary: 'Patch the pig was not for food, he had been donated to the farm to be cared for on site.' [Fieldnotes, 9 April 2015]. Yet with other farms, the animals are simply there until they are ready to go to slaughter: 'A discussion was started based on the farmer's lunch: Snowflake the cockerel. Snowflake had got the chop the day previously - literally! The farmer had taken the bird's head off with an axe on a chopping block.' [Fieldnotes, 22 May 2015]. This harks back to Malamud's (2013) point that health can be seen as just another resource to be harvested from non-humans; it seems jarring to describe these spaces as therapeutic when, for the non-humans involved, they are often spaces of death.

Though there is perhaps an argument to be made that whilst being involved in an agricultural system may not necessarily end well for animals, they do conceivably experience certain benefits from being involved in the therapeutic space of a care farm: 'I think also because we're with the animals all the time, they are more used to people being around, which means that sort of catching them for slaughter, 'oh look, there's my friends, I'll just get in this trailer', it makes it less stressful for them, collecting eggs from the chickens as well...they're more used to us being in there, they're not frightened of us' $[\mathrm{P}$, assistant manager of a care farm, East England]. 'The lambs are very tame, and run up to the fence when people approach, this is possibly due to the amount of bottle feeding that goes on at the farm, but could also be from the daily socialisation that the animals have with care farm members... The sheep are again, very tame, and come running over as we approach with the wheelbarrow full of food.' [Fieldnotes, 9 April 2015]. 


\section{R. Gorman}

The more regular contact with humans as a result of the therapeutic practices engaged with on the farm has the potential to create a less stressful and more relaxed experience for the animals - despite their ultimate purpose and destination as food products.

We must also recognise animals' mobilities. Whilst some of the farm animals may live permanently within the space of the care farm, others are perhaps simply passing through the space, briefly entangling with the assemblage, unaware and unengaged. 'Squirrels running through the trees are a common sight at the farm, people will often break off mid-conversation to watch them.' [Fieldnotes, 22 May 2015]. This becomes particularly interesting when we begin to think about barriers and boundaries, and the non-humans that people choose (and do not choose) to invite into therapeutic spaces. Indeed, recognising animals' mobilities forces a consideration of the fluid and porous nature of therapeutic spaces, and that often, humans have little choice in the species that become entangled in (un)therapeutic ways in spaces of care.

There are also practical limitations and caveats to inter-species contact to consider: 'We dip our feet all the time now, but our chickens were ill a lot more, coz obviously you've got more people going in there all the time' [Y, manager of a care farm, East England]. Animals can become stressed or panicked; certain species require, if not specific technique, then at least a level of confidence, during physical and hands-on encounters; there is clearly the potential for conflict between achieving high animal welfare and providing care for the human participants on the farm. As a result, animals are often modified to make them 
suitable for human based therapeutic contact, from halter training cattle, to wing clipping chickens. Species is an important driver for the role and experiences of non-humans in therapeutic spaces.

Participants will often attempt to empathize, relate to, and consider the experiences of the non-humans who have come to be enmeshed within the therapeutic assemblage: 'They [the animals] value the relationship with us as we do with them' [B, farmer, Southwest England], 'We try to build up more of a relationship with the animals' $[\mathrm{Y}$, manager of a care farm, East England]. And whilst there are arguments to be made for utilising these day-to-day dwelt relationships, and garnering an understanding from co-relationality (Johnston 2008), overly relying on human participants cannot adequately tell us about multispecies experiences of shared spaces of care. Anthropomorphism can begin to creep into our discourse; people ultimately do not know and cannot speak for the experience of animals within a therapeutic space.

However, the therapeutic use of other species does not have to be anthropocentric or utilitarian. In the same way in which therapy animals can provide care and services to humans with various health conditions, humans can provide care and services to non-humans with specific needs and past experiences. Yet, equally and importantly, neither is this about framing care for non-humans as 'with strings attached' (DeVerteuil 2015, p.49), selfishly requiring some form of benefit for the anthropos in return for a stewardship of Gaia's injured children. 
As an example of a more post-human deployment of care in this way, one project involved rescuing horses that had been neglected or abandoned, rehabilitating and training them. This rehabilitation work specifically involved working with disengaged and vulnerable groups: 'There was a boy with ADHD, and we said, 'you've got to really consider your behaviour, no sudden movements', so it was amazing to see him, having to really manage himself, which he did beautifully and then when he got a horse to do something, and then he rewarded it and clicked it, he was like 'wow', he saw, I guess he saw the benefits of realising his actions on others, and how his behaviour, if its altered, might have a positive effect on others, so that, for him, was massive' [J, staff member taking students with learning disabilities to animal projects, West Wales]. The equine participants receive a level of care, training, and socialisation, rehabilitating and working to improve their lives, whilst also providing important affective encounters for vulnerable and at-need human social groups. The project actively creates a therapeutic space for the non-human participants, as well as providing a therapeutic space for human participants; a post-human therapeutic landscape, that manoeuvres around the traditional human-centric and utilitarian approach to animals within therapeutic spaces, recognising relationships of mutualism, rather than amensalism, parasitism, or commensalism.

The same scheme also involved the creation of a multispecies reading programme, where children and adults learn to read by reading to animals in animal shelters, helping them to become socialised to human companionship, in the hope of finding a permanent home, whilst allowing the readers (often young adults with special educational needs) to overcome barriers to learning to read: 
'They don't feel that they're reading for themselves, they don't feel like they're reading coz they're thick... you're breaking down a barrier... they're reading to the cat, they're no longer learning to read because they failed in school... they are reading to the cat, because the cat needs to be read to, the cat needs company, they're helping the cat' [J, staff member taking students with learning disabilities to animal projects, West Wales].

Obviously, arguments can be made regarding the egalitarianism of the affective exchanges in these scenarios, however, this more biosocial, mutually beneficial framing of therapeutic affect provides an interesting way to explore and critically understand human-animal relations in a wide variety of therapeutic spaces.

\section{Conclusions and future directions}

This paper has attempted to bridge the gap between animal geographies and therapeutic geographies in order to 'bring the animals back in' to understandings of therapeutic spaces. I have demonstrated how non-human presence can actively create and facilitate a therapeutic engagement with place, and have begun to envisage how we can begin to think about therapeutic spaces as multispecies spaces, with non-humans as not just co-constituents, but also coparticipants of therapeutic landscapes.

Vidal de La Blache (1922) wrote that we should not consider 'the Earth as the scene on which the activity of man unfolds itself, without reflecting that this 


\section{R. Gorman}

scene is itself living' - and this is certainly true for studies of therapeutic spaces. There is a need to examine the roles of more-than-human elements and actants in creating the relations which lead to space 'becoming therapeutic'; an emergence co-constituted, or, to follow Haraway (2008), a 'becoming therapeutic with' non-humans. There is a need for more research that further unpacks the heterogeneity of therapeutic spaces, and avoids an anthropocentric gaze when examining the health benefits of place.

There are many interesting therapeutic spaces that are based around human-animal relationships. From the care farms discussed earlier in this paper, to the increasing numbers of 'puppy rooms' setting up on campuses across British universities to help students deal with exam stress (whilst allowing guide dogs in-training to become socialised to large groups of people) (BBC 2015), or even the multispecies reading programs (similar to the empirical example briefly mentioned above). These few examples ${ }^{1}$ highlight ways in which we can begin to think about the therapeutic qualities humans can provide to other species, decentring humanity in discussions of therapeutic spaces and better integrating animals into therapeutic geographies. The benefits of an increased focus on animals is not solely limited to discussions of therapeutic landscapes, and has the potential to create new agendas within wider aspects of health based geographic research given the fields interest in engaging with socio-ecological conceptualisations of health, interrogating the experiential aspects of place, the crafting of treatment settings, and the consumption and production of care (Kearns and Collins 2009). There is also the potential for geographies of therapeutic spaces to increasingly engage with the multi-disciplinary framework 
of 'One Health', from where the earlier discussed idea of zooeyia originates from. The critiques of zooeyia and its problematic retention of a human-centric focus highlight the opportunity for geographers to increasingly engage with and contribute to multi-disciplinary discussions about the interdependence of human, animal, and ecosystem health.

However, there is also a need to remember that 'animal' is not a homogenous grouping, instead comprised of diverse and specific species, responding in specific ways with a multiplicity of relations to humans (Bear 2011). We should begin to consider how individual species and non-humans impact therapeutic spaces. What are the roles of more 'unfamiliar' species in contributing to experiences of health and space?

As well as these specific questions, beginning to investigate animals and therapeutic spaces in more detail may bring about methodological challenges; how can one evoke the embodied experience of animals, whilst also acknowledging one's own anthropomorphism. Textual and linguistic strategies inherently favour human participants, leaving keepers, owners, and farmers to speak for animals (Bear et al. Forthcoming). Kirksey and Helmreich (2010) note the emergence of 'multispecies ethnography' as a means of bringing creatures previous on the margins more vividly into the foreground. An interdisciplinary method emergent from the intersections between environmental studies, science and technology studies, and animal studies, multispecies ethnography provides a way of rethinking the nature/culture divide and acknowledging that interactions between species are not purely mediated through a level of human involvement 
(Kirksey and Helmreich 2010; Smart 2014)2. Multispecies ethnographies of therapeutic spaces could highlight the diversity of different ways in which different actants engage with place.

However, there are some caveats to multispecies ethnography to consider; whilst the method aids in creating a reconceptualised social constituted of more than just human actants, it fails to capture a more expanded range of diverse more-than-human actants (Smart 2014), artifacts, technologies, and elemental forces (Bennett 2005), in favour of a more zoetic approach. When thinking about the future of therapeutic landscapes research, multispecies ethnography's omission of machinery and technologies in favour of mortal actants is particularly problematic given the increasing ways in which robotic technologies are becoming prevalent in formal spaces of care (Pym 2015). There is a need for geographies of therapeutic spaces to take up Del Casino's (2015) call for interrogating the role of robots in the production of 'caring spaces'. Of particular interest is the often hybrid nature of these robotic care-technologies, which draw on the animality and charisma of animal species, such as 'Paro', the robotic baby harp seal, intended to mimic aspects of animal assisted therapy (Calo et al. 2011).

There are also theoretical aspects to consider, a need to begin to think about the kind of flat ontologies that will facilitate the exploration of these spaces by removing the duality of human-animal. As discussed earlier, the use of assemblage theory suggested by Foley (2014) which I have built on and developed within this article, could provide a useful framework, introducing an 
approach that enables an understanding of how rather than static and absolute phenomena, therapeutic spaces can instead be considered to emerge relationally constituted by a coming together of heterogeneous elements, creating a multiplicity of fluid, contingent, and indeterminate therapeutic spaces.

By paying attention to both non-human agency and non-human experience, we can make a difference to how we discuss therapeutic landscapes, developing a critical understanding of the role of non-human animals as both coconstituents and co-participants of therapeutic spaces, moving from framing therapeutic spaces - and the animals within them - purely in relation to human needs and desires, leading to new, and exciting directions and questions for research on therapeutic spaces.

\section{Acknowledgements}

I am grateful to Christopher Bear, Geoffrey DeVerteuil, three anonymous referees, and audiences at the 'Exploring Therapeutic Spaces' session at the Nordic Geographers Meeting 2015, and the 'Nonhuman Animals and Posthuman Futures Symposium' at the University of Warwick, who all gave insightful feedback on earlier versions of this paper.

\section{Funding}

This research was conducted as part of a 3 year PhD scholarship, jointly funded by an Economic and Social Research Council studentship (grant reference ES/J500197/1) and a Cardiff University President's Scholarship. 


\section{Notes}

1 An additional example, which particularly resonates with this author, is Haraway's (2008) call to involve humans with haemophilia in the care of the canine haemophiliacs that have been specifically bred to provide research opportunities into bleeding disorders, helping to establish modern haemophilia management.

2 Intriguing examples of this method of writing culture in the Anthropocene include Haraway's (2008) post-human relationship with her Australian shepherd, Lien's (2015) slippery accounts of salmon aquaculture, and Candea's (2010) encounters with charismatic celebrity meerkats. 


\section{References}

Adam, K. L. (2006) Community supported agriculture. ATTRA-National Sustainable Agriculture Information Service, Butte, MT.

Anderson, B. and McFarlane, C. (2011) Assemblage and geography, Area 43: 1247.

Andrews, G. J. (2004) (Re) thinking the dynamics between healthcare and place: therapeutic geographies in treatment and care practices, Area 36: 307-18.

Barba, B. E. (1995) The positive influence of animals: animal-assisted therapy in acute care, Clinical Nurse Specialist 9: 199-202.

BBC. (2015) Bristol university's 'puppy room' to combat exam stress, http://www.bbc.co.uk/news/uk-england-bristol-32707572 (accessed 28/01/2016 2016).

Bear, C. (2011) Being Angelica? Exploring individual animal geographies, Area 43: 297-304.

Bear, C. (2013) Assembling the sea: materiality, movement and regulatory practices in the Cardigan Bay scallop fishery, Cultural Geographies 20: 21-41. Bear, C. and Eden, S. (2011) Thinking like a fish? Engaging with nonhuman difference through recreational angling, Environment and Planning-Part D 29: 336-52.

Bear, C., Wilkinson, K. and Holloway, L. (Forthcoming) Visualising humananimal-technology relations: fieldnotes, still photography and digital video on the robotic dairy farm, Society \& Animals.

Beck, A. M. and Katcher, A. H. (2003) Future directions in human-animal bond research, American Behavioral Scientist 47: 79-93.

Bennett, J. (2005) The agency of assemblages and the North American blackout, Public Culture 17: 445-65.

Berget, B. and Braastad, B. O. (2008) Theoretical Framework for Animal-Assisted Interventions-Implications for Practice, Int J Ther Communities 29: 323-37. Calo, C. J., Hunt-Bull, N., Lewis, L. and Metzler, T. (2011) Ethical Implications of Using the Paro Robot, 2011 AAAI Workshop (WS-2011-2012), San Francisco, pp. 20-4.

Candea, M. (2010) "I fell in love with Carlos the meerkat": Engagement and detachment in human-animal relations, American Ethnologist 37: 241-58. Chang, C. and Relf, D. (2004) Psychophysiological responses to different landscape settings and a comparison of cultural differences, Expanding roles for horticulture in improving human well-being and life quality, a proceedings of the XXVI International Horticultural Congress, Toronto, Canada, 11-17 August, 2004. International Society for Horticultural Science (ISHS), pp. 57-65.

Collins, D. and Kearns, R. (2007) Ambiguous Landscapes: Sun, Risk and Recreation on New Zealand Beaches, in Williams, A. (ed.) Therapeutic Landscapes. Ashgate Publishing Company, Hampshire, pp. 15-31. Conradson, D. (2005) Landscape, care and the relational self: Therapeutic encounters in rural England, Health \& Place 11: 337-48.

Conradson, D. (2007) The Experiential Economy of Stillness, in Williams, A. (ed.) Therapeutic Landscapes. Ashgate Publishing Company, Hampshire, pp. 33-48. 
Cooley, J. P. (1996) Community Supported Agriculture: A Study of Shareholders' Dietary Patterns, Food Practices, and Perceptions of Farm Membership. University of Massachusetts at Amherst, Unpublished Masters Thesis.

Cooley, J. P. and Lass, D. A. (1998) Consumer benefits from community supported agriculture membership, Review of Agricultural Economics 20: 227-37.

Csikszentmihalyi, M. (2009) Flow. HarperCollins, London.

Cudworth, E. (2011) Social Lives with Other Animals: Tales of Sex, Death and Love. Palgrave Macmillan, New York.

Curtis, P. S. (2012) Space, Place and Mental Health. Ashgate Publishing Limited, Surrey.

Curtis, S., Gesler, W., Smith, G. and Washburn, S. (2000) Approaches to sampling and case selection in qualitative research: examples in the geography of health, Social Science \& Medicine 50: 1001-14.

Del Casino, V. J. (2015) Social geographies II: Robots, Progress in Human Geography.

DeVerteuil, G. (2015) Resilience in the Post-welfare Inner City: Voluntary Sector Geographies in London, Los Angeles and Sydney. Policy Press.

DeVerteuil, G., Wilton, R. and Klassen, S. (2007) Making Clean and Sober Places:

The Intersections of Therapeutic Landscapes and Substance Abuse Treatment, in Williams, A. (ed.) Therapeutic Landscapes. Ashgate Publishing Company, Hampshire, pp. 77-94.

Dobbs, G. R. (1997) Interpreting the Navajo sacred geography as a landscape of healing, Pennsylvania Geographer 35: 136-50.

Doughty, K. (2013) Walking together: The embodied and mobile production of a therapeutic landscape, Health \& Place 24: 140-6.

Dunkley, C. M. (2009) A therapeutic taskscape: Theorizing place-making, discipline and care at a camp for troubled youth, Health \& Place 15: 88-96.

Foley, R. (2014) The Roman-Irish Bath: Medical/health history as therapeutic assemblage, Social Science \& Medicine 106: 10-9.

Foley, R. and Kistemann, T. (2015) Blue space geographies: Enabling health in place, Health \& Place 35: 157-65.

Foley, R., Wheeler, A. and Kearns, R. (2011) Selling the colonial spa town: The contested therapeutic landscapes of Lisdoonvarna and Te Aroha, Irish Geography 44: 151-72.

Gesler, W. M. (1992) Therapeutic landscapes: Medical issues in light of the new cultural geography, Social Science \& Medicine 34: 735-46.

Gesler, W. M. (1996) Lourdes: healing in a place of pilgrimage, Health \& Place 2: 95-105.

Gesler, W. M. (1998) Bath as a Healing Place, in Kearns, R. A. and Gesler, W. M. (eds.) Putting health into place: Landscape, identity, and well-being. Syracruse University Press, New York, pp. 17-35.

Gesler, W. M. (2003) Healing Places. Rowman \& Littlefield, Oxford.

Ginn, F. (2013) Sticky lives: slugs, detachment and more - than - human ethics in the garden, Transactions of the Institute of British Geographers 39: 532-44.

Groh, T. and McFadden, S. (2000) Farms of Tomorrow Revisited: Community

Supported Farms, Farm Supported Communities. Bio-Dynamic Farming \& Gardening Association, Incorporated, Kimberton. 
Hanrahan, C. (2014) Integrative Health Thinking and the One Health Concept: Is Social Work All for 'One'or 'One'for All?, in Ryan, T. (ed.) Animals in social work: why and how they matter. Palgrave Macmillan, Basingstoke, UK, pp. 32-47. Haraway, D. J. (2008) When species meet. University of Minnesota Press Minneapolis.

Hassink, J. (2002) Combining agricultural production and care for persons with disabilities: a new role of agriculture and farm animals, Farming and Rural Systems Research and Extension. Local Identities and Globalisation. Fifth IFSA European Symposium, Florence, Italy, pp. 8-11.

Hassink, J., Elings, M., Zweekhorst, M., van den Nieuwenhuizen, N. and Smit, A. (2010) Care farms in the Netherlands: Attractive empowerment-oriented and strengths-based practices in the community, Health \& Place 16: 423-30.

Hassink, J., Hulsink, W. and Grin, J. (2012) Care Farms in the Netherlands: An Underexplored Example of Multifunctional Agriculture-Toward an Empirically Grounded, Organization - Theory - Based Typology, Rural Sociology 77: 569600.

Hine, R. E. (2007) Care Farming in the UK - Recent research findings on i) the scope and range of Care Farms in the UK and ii) pilot study on the pyschological health and well-being benefits of care farming in the UK, in Gallis, C. (ed.) Proceedings from the 1st European COST Action 866 conference : Green care in Agriculture: Health effects, Economics and Policies. University Studio Press, Vienna p. 42.

Hine, R. E., Peacock, J. and Pretty, J. (2008) Care Farming in the UK: Contexts, Benefits and Links with Therapeutic Communities, Int J Ther Communities 29: 245-60.

Hodgson, K. and Darling, M. (2011) Zooeyia: an essential component of "One Health", The Canadian Veterinary Journal 52: 189-91.

Hoyez, A.-C. (2007) The 'world of yoga': The production and reproduction of therapeutic landscapes, Social Science \& Medicine 65: 112-24.

Ilbery, B. and Bowler, I. (1998) From agricultural productivism to postproductivism. Addison Wesley Longman Ltd.

Ingen, C. v. (2004) Therapeutic landscapes and the regulated body in the Toronto Front Runners, Sociology of Sport Journal 21: 253-69.

Jadhav, S. and Barua, M. (2012) The Elephant Vanishes: Impact of humanelephant conflict on people's wellbeing, Health \& Place 18: 1356-65.

Johnston, C. (2008) Beyond the clearing: towards a dwelt animal geography, Progress in Human Geography 32: 633-49.

Kearns, R. and Collins, D. (2009) Health Geography, in Brown, T., McLafferty, S. and Moon, G. (eds.) A Companion to Health and Medical Geography. Wiley, Oxford, pp. 15-32.

Kearns, R. A. and Gesler, W. M. (1998) Putting health into place: Landscape, identity, and well-being. Syracuse University Press, New York.

Kearns, R. A. and Joseph, A. E. (1993) Space in its place: Developing the link in medical geography, Social Science \& Medicine 37: 711-7.

Kellert, S. R. (1996) The Value of Life: Biological Diversity and Human Society. Island Press, Washington, DC.

Kirksey, S. and Helmreich, S. (2010) The emergence of multispecies ethnography, Cultural anthropology 25: 545-76. 
Law, J. and Miele, M. (2011) Animal Practices, in Carter, B. and Charles, N. (eds.) Human and Other Animals: Critical Perspectives. Palgrave Macmillan, Hampshire, pp. 50-65.

Laws, J. (2009) Reworking therapeutic landscapes: The spatiality of an 'alternative'self-help group, Social Science \& Medicine 69: 1827-33.

Leach, M. A., Fairhead, J. R. and Millimouno, D. (2008) New therapeutic landscapes in Africa: Parental categories and practices in seeking infant health in the Republic of Guinea, Social Science \& Medicine 66: 2157-67.

Leck, C., Evans, N. and Upton, D. (2014) Agriculture-Who cares? An investigation of 'care farming'in the UK, Journal of Rural Studies 34: 313-25.

Lien, M. E. (2015) Becoming Salmon: Aquaculture and the Domestication of a Fish. University of California Press, Oakland.

Lorimer, H. (2006) Herding memories of humans and animals, Environment and Planning D 24: 497-518.

Low, S. M. and Altman, I. (1992) Place attachment. Springer, New York.

Malamud, R. (2013) Service Animals: Serve us animals: Serve us, animals, Social

Alternatives 32: 34-40.

Mallon, G. P. (1994) Cow as co-therapist: Utilization of farm animals as

therapeutic aides with children in residential treatment, Child and Adolescent

Social Work Journal 11: 455-74.

Marcus, C. C. and Barnes, M. (1999) Healing Gardens: Therapeutic Benefits and

Design Recommendations. Wiley, New York.

Milligan, C. (2007) Restoration or Risk? Exploring the Place of the Common

Place, in Williams, A. (ed.) Therapeutic Landscapes. Ashgate Publishing Company, Hampshire, pp. 255-72.

Milligan, C. and Bingley, A. (2007) Restorative places or scary spaces? The impact of woodland on the mental well-being of young adults, Health \& Place 13: 799-

811.

Milligan, C., Gatrell, A. and Bingley, A. (2004) 'Cultivating health': therapeutic landscapes and older people in northern England, Social Science \& Medicine 58: 1781-93.

Milligan, C. and Wiles, J. (2010) Landscapes of care, Progress in Human Geography 34: 736-54.

Milne, A. A. (1954) Winnie the Pooh. Puffin Books, London.

Morita, E., Fukuda, S., Nagano, J., Hamajima, N., Yamamoto, H., Iwai, Y.,

Nakashima, T., Ohira, H. and Shirakawa, T. (2007) Psychological effects of forest environments on healthy adults: Shinrin-yoku (forest-air bathing, walking) as a possible method of stress reduction, Public health 121: 54-63.

Murdoch, J. (2006) Post-structuralist Geography: A Guide to Relational Space.

SAGE Publications, London.

Odendaal, J. (2000) Animal-assisted therapy-magic or medicine?, Journal of psychosomatic research 49: 275-80.

Palka, E. (1999) Accessible Wildernes as a Therapeutic Landscape, in Williams, A. (ed.) Therapeutic Landscapes: The Dynamic Between Place and Wellness.

University Press of America, Maryland, pp. 29-52.

Philo, C. and Wilbert, C. (2000) Animal Spaces, Beastly Places. Taylor \& Francis, New York.

Pitt, H. (2014) Therapeutic experiences of community gardens: putting flow in its place, Health \& Place 27: 84-91. 
Pym, H. (2015) Is this cuddly robot coming to a care home near you?, http://www.bbc.co.uk/news/health-34271927 (accessed 28/01/2016 2016). Rose, E. (2012) Encountering place: A psychoanalytic approach for understanding how therapeutic landscapes benefit health and wellbeing, Health \& Place 18: 1381-7.

Scholl, S. and Demattio, L. (2007) Animal Assisted Therapy, Pedagogics and Activities with Farm Animals, in Gallis, C. (ed.) Proceedings from the 1st European COST Action 866 conference : Green care in Agriculture: Health effects, Economics and Policies. University Studio Press, Vienna pp. 43-4.

Sempik, J. (2008) Editorial: Green Care: A Natural Resource for Therapeutic Communities, Int J Ther Communities 29: 222-6.

Smart, A. (2014) Critical perspectives on multispecies ethnography, Critique of Anthropology 34: 3-7.

Smith, M. and Davidson, J. (2006) It Makes My Skin Crawl...': The Embodiment of Disgust in Phobias of 'Nature, Body \& Society 12: 43-67.

Stagl, S. (2002) Local organic food markets: potentials and limitations for contributing to sustainable development, Empirica 29: 145-62.

Thurber, C. and Malinowski, J. (1999) Summer Camp as a Therapeutic Landscape, in Williams, A. (ed.) Therapeutic Landscapes: The Dynamic Between Place and Wellness. University Press of America, Maryland, pp. 53-70.

Tuan, Y. F. (1980) Landscapes of Fear. Blackwell, New York.

Tyson, M. M. (1998) The healing landscape: therapeutic outdoor environments. McGraw-Hill Professional Publishing, New York. Urbanik, J. (2012) Placing Animals: An Introduction to the Geography of HumanAnimal Relations. Rowman \& Littlefield Publishers, New York.

Vidal de La Blache, P. (1922) Principes de géographie humaine [Principles of Human Geography]. Colin, Paris.

Wilkie, R. (2013) Multispecies scholarship and encounters: Changing assumptions at the human-animal nexus, Sociology 49: 323-39.

Wilkie, R. and McKinnon, A. (2013) George Herbert Mead on Humans and Other Animals: Social Relations After Human-Animal Studies, Sociological Research Online 18: 19.

Williams, A. (1999) Therapeutic Landscapes: The Dynamic Between Place and Wellness. University Press of America, Maryland.

Williams, A. (2007) The Continuing Maturation of the Therapeutic Landscape Concept, in Williams, A. (ed.) Therapeutic Landscapes. Ashgate Publishing Company, Hampshire, pp. 1-12.

Williams, A. (2010) Spiritual therapeutic landscapes and healing: A case study of St. Anne de Beaupre, Quebec, Canada, Social Science \& Medicine 70: 1633-40.

Wilson, K. (2003) Therapeutic landscapes and First Nations peoples: an exploration of culture, health and place, Health \& Place 9: 83-93.

Wilton, R. and DeVerteuil, G. (2006) Spaces of sobriety/sites of power: examining social model alcohol recovery programs as therapeutic landscapes, Social Science \& Medicine 63: 649-61.

Wolch, J. and Emel, J. (1995) Bringing the animals back in, Environment and Planning D: Society and Space 13: 632-6.

Wood, V. J., Gesler, W., Curtis, S. E., Spencer, I. H., Close, H. J., Mason, J. and Reilly, J. G. (2015) 'Therapeutic landscapes' and the importance of nostalgia, solastalgia, 
42 R. Gorman

salvage and abandonment for psychiatric hospital design, Health \& Place 33: 839.

Zeisel, J. and Tyson, M. M. (1999) Alzheimer's Treatment Gardens, in Marcus, C. C. and Barnes, M. (eds.) Healing Gardens: Therapeutic Benefits and Design

Recommendations. Wiley, New York, pp. 437-505. 